\title{
METODE MODIFIED JACKKNIFE RIDGE REGRESSION DALAM PENANGANAN MULTIKOLINIERITAS (STUDI KASUS INDEKS PEMBANGUNAN MANUSIA DI JAWA TENGAH)
}

\author{
Arya Huda Arrasyid ${ }^{1}$, Dwi Ispriyanti ${ }^{2}$, Abdul Hoyyi ${ }^{3}$ \\ ${ }^{1}$ Mahasiswa Dapartemen Statistika FSM Universitas Diponegoro \\ ${ }^{2,3}$ Staff Pengajar Departemen Statistika FSM Universitas Diponegoro \\ e-mail aryahuda123@gmail.com
}

\begin{abstract}
The human development index is a value where the value showed the measure of living standards comparison in a region. The Human Development Index is influenced by several factors, one of them is the education factor that is the average years of schooling and expected years of schooling. A statistical method to find the correlation between the independent variable and the dependent variable can be conducted using the linear regression method. Linear regression requires several assumptions, one of which is the multicollinearity assumption. If the multicollinearity assumption is not fulfilled, another alternative is needed to estimate the regression parameters. One method that can be used to estimate regression parameters is the ridge regression method with an ordinary ridge regression estimator. Ordinary ridge regression then developed more into several methods, such as generalized ridge regression, jackknife ridge regression, and modified jackknife ridge regression method. The generalized Ridge Regression method causes a reduction to variance in linear regression, while the jackknife ridge regression method is obtained by resampling jackknife process on the generalized ridge regression method. Modified jackknife ridge regression is a combination of generalized ridge regression and jackknife ridge regression method. In this journal, the three ridge regression methods will be compared based on the Mean Squared Error obtained in each method. The results of this study indicate that the jackknife ridge regression method has the smallest MSE value.
\end{abstract}

Keywords: Generalized Ridge Regression, Jackknife Ridge Regression, Modified Jackknife Ridge Regression, Multicolinearity

\section{PENDAHULUAN}

\section{Latar Belakang}

Indeks pembangunan manusia ialah sebuah nilai dimana nilai tersebut menunjukkan besarnya ukuran perbandingan standar hidup di suatu wilayah. Indeks pembangunan manusia berlandaskan terhadap beberapa ukuran yaitu kualitas hidup suatu wilayah yang berupa tingkat kesahatan dan lama hidup penduduknya, faktor pendidikan yang berupa rata-rata lama bersekolah maupun harapan lama bersekolah dalam suatu wilayah, ukuran selanjutnya adalah ukuran hidup layak berupa nilai produk domestic bruto sebagai ukuran besarnya daya beli penduduknya (UNDP, 1990). Penelitian ini memperlihatkan bahwasannya memang terdapat pengaruh faktor pendidikan terhadap IPM. Analisis yang digunakan untuk mengetahui hubungan variabel bebas dan variabel terikat adalah analisis regresi linier.

Analisis Regresi Linier adalah metode yang digunakan untuk mengetahui hubungan variabel bebas (X) dengan variabel terikat (Y). Menurut Manurung et al. (2005), regresi linier harus memenuhi beberapa asumsi, salah satunya adalah asumsi multikolinieritas. Apabila asumsi multikolinieritas tidak terpenuhi, diperlukan alternatif lain untuk menaksirkan parameter regresi. Salah satunya adalah dengan menaksirkan regresi menggunakan metode regresi ridge dengan penaksir ordinary ridge regression. Ordinary ridge regression dikembangkan menjadi beberapa metode, yaitu metode generalized ridge regression, jackknife ridge regression, dan modified jackknife ridge regression. Metode generalized ridge regression menyebabkan pengurangan varian pada regresi linier sedangkan metode jackknife ridge regression didapatkan dengan melakukan proses 
resampling jackknife pada metode generalized ridge regression. Modified jackknife ridge regression merupakan gabungan dari metode generalized ridge regression dan jackknife ridge regression. Estimasi modified jackknife ridge regression dilakukan dengan mengalikan parameter yang didapatkan pada estimasi generalized ridge regression dan jackknife ridge regression (Khurana et al., 2014).

Penelitian ini bertujuan untuk melakukan penanganan masalah multikolinieritas dengan menggunakan metode generalized ridge regression (GRR), jackknife ridge regression (JRR), dan modified jackknife ridge regression (MJRR), serta mendapatkan model Regresi ridge dengan metode tersebut.

\section{TINJAUAN PUSTAKA}

\subsection{Regresi Linier Berganda}

Regresi linier memiliki fungi meramalkan Y, dengan memeriksa hubungannya dengan variabel lain (Gujarati, 1991). Gujarati (1991) mengemukakan model regresi linier sampel berganda dapat dituliskan:

$$
\mathrm{Y}_{\mathrm{i}}=\beta_{0}+\beta_{1} x_{i 1}+\beta_{2} x_{i 2}+\beta_{3} x_{i 3}+\ldots+\beta_{k} x_{i k}+\varepsilon_{i}
$$

Keterangan:

i : $1,2,3, \ldots, n$ (banyak data)

$\mathrm{j}: 1,2,3, \ldots, \mathrm{k}$ (banyak variabel bebas)

$\mathrm{P}: \mathrm{k}+1$

$\mathrm{P}$ : banyaknya parameter $\left(\beta_{0}, \beta_{1}, \beta_{2}, \beta_{3}, \ldots, \beta_{k}\right)$

$\mathrm{X}_{\mathrm{ij}}$ : variabel bebas

$\mathrm{Y}_{\mathrm{i}}$ : variabel terikat

$\beta_{0}:$ konstanta

$\beta_{j}:$ koefisien regresi

$\varepsilon$ : besarnya galat (error)

Penaksir regresi linier dapat ditaksirkan dengan menggunakan ordinary least square. Menurut Gujarati (1991) penaksir OLS diperoleh dengan meminimumkan jumlah kesalahan atau error kuadrat, sehingga diperoleh penaksir untuk ordinary least square adalah

$$
\widehat{\boldsymbol{\beta}}=\left(\mathbf{X}^{\mathbf{T}} \mathbf{X}\right)^{-1} \mathbf{X}^{\mathbf{T}} \mathbf{Y}
$$

\subsubsection{Standarisasi Variabel Regresi}

Proses standarisasi dilakukan dengan mengurangi data pengamatan dengan nilai rata-rata variabel data kemudian dibagi dengan standar deviasi variabel data itu sendiri (Manurung et al., 2005). Sehingga berdasarkan pernyataan tersebut maka standarisasi data tersebut dapat dirumuskan:

$$
X^{*}=\frac{y_{i}-\bar{Y}}{S_{Y}} \text { dan } Y^{*}=\frac{x i-\bar{X}}{S_{x}}
$$

Menurut Kutner et al. (2005) model regresi standarisasi (standardized regression model) dapat dituliskan menjadi:

$$
Y_{i}^{*}=\beta_{1}^{*} X_{i 1}^{*}+\beta_{2}^{*} X_{i 2}^{*}+\ldots+\beta_{k}^{*} X_{i k}^{*}+\varepsilon
$$

Adapun hubungan $\beta_{1}^{*}, \beta_{2}^{*}, \ldots, \beta_{k}^{*}$ dengan $\beta_{0}, \beta_{1}, \beta_{2}, \ldots, \beta_{k}$ dapat dituliskan dengan sebagai berikut:

$$
\beta_{k}=\left(\frac{S_{Y}}{S_{k}}\right) \beta_{k}^{*}
$$




$$
\beta_{0}=\bar{Y}-\beta_{1} \bar{X}_{i 1}-\ldots-\beta_{k} \bar{X}_{i k}
$$

\subsubsection{Uji Koefisien Regresi Linier Berganda}

\section{Uji F}

Uji $\mathrm{F}$ digunakan untuk menguji secara bersama-sama pengaruh variabel bebas terhadap variabel terikat (Kurniawan \& Yuniarto, 2016). Adapun untuk hipotesisnya dapat dituliskan sebagai berikut:

$\mathrm{H}_{0}: \beta_{1}=\beta_{2}=\ldots=\beta_{\mathrm{k}}=0$ (seluruh variabel bebas secara simultantidak berpengaruh terhadap variabel terikat)

$\mathrm{H}_{1}: \beta_{\mathrm{j}} \neq 0$ (seluruh variabel bebas secara simultan berpengaruh terhadap variabel terikat, untuk $\mathrm{j}=1,2,3, \ldots, \mathrm{k})$,

Statistik ujinya yaitu:

$$
\mathrm{F}_{\text {hitung }}=\frac{S S_{R} / k}{S S_{E} /(n-k-1)}=\frac{M S R}{M S E}
$$

Adapun kriteria penolakannya yaitu $\mathrm{H}_{0}$ ditolak jika $\mathrm{F}_{\text {hitung }}>\mathrm{F}_{(\alpha, k, n-k-1)}$ atau $p$-value $<\alpha$.

\section{Uji t (Uji Koefisien Regresi secara Parsial)}

Uji t merupakan suatu pengujian secara parsial (satu-satu) yang bertujuan untuk mengetahui pengaruh variabel independen memiliki pengaruh terhadap variabel dependen (Kim, 2015). Adapun hipotesis untuk uji t ialah:

$\mathrm{H}_{0}: \beta_{\mathrm{k}}=0$ (masing-masing variabel bebas tidak berpengaruh signifikan terhadap variabel terikat)

$\mathrm{H}_{1}: \beta_{\mathrm{k}} \neq 0$ (masing-masing variabel bebas berpengaruh signifikan terhadap variabel terikat)

Statistik ujinya adalah:

$$
\text { thitung }=\frac{\hat{\beta}_{k}}{\operatorname{Se}\left(\hat{\beta}_{k}\right)} \text {; }
$$

\subsubsection{Uji Asumsi Regresi Linier Berganda Normalitas}

Gujarati (1991) mengemukakan regresi linier normal mengasumsikan bahwa setiap $\varepsilon_{\mathrm{i}}$ berdistribusi secara normal:

$$
\begin{aligned}
& \text { Rata-rata }: \mathrm{E}\left(\varepsilon_{\mathrm{i}}\right)=0 \\
& \text { Varians }: \mathrm{E}\left(\varepsilon_{\mathrm{i}}^{2}\right)=\sigma^{2}
\end{aligned}
$$

Sehingga distribusi normal errornya dapat dinyatakan sebagai $\boldsymbol{\varepsilon}_{\mathbf{i}} \sim \mathrm{N}\left(0, \sigma^{2}\right)$. Salah satu uji formal untuk menguji asumsi normalitas adalah dengan melakukan uji Kolmogo rovSmirnov.

\section{Homoskedastisitas}

Adapun secara simbolis heteroskedastisitas dapat didefinisikan sebagai berikut :

$$
\mathrm{E}\left(\varepsilon_{\mathrm{i}}\right)=\sigma_{i}^{2}
$$

Menurut Manurung et al. (2005) apabila heteroskedastisitas terjadi maka metode estimasi OLS tidak dapat digunakan, sehingga diperlukan alternatif lain seperti weighted least square atau bisa juga dengan general least square. Gujarati (1991) menyebutkan bahwa heteroskdastisitas dapat dicek dengan menggunakan uji glejser. 
Uji glejser dilakukan dengan mengkorelasikan nilai absolut residual dengan masing-masing variabel.

Untuk hipotesis dari uji glejser dapat dituliskan sebagai berikut:

$\mathrm{H}_{0}$ : terjadi homoskedastisitas

$\mathrm{H}_{1}$ : terjadi heteroskedastisitas

Sedangkan statistik ujinya untuk uji glejser dapat dicari dengan nilai t, yang diformulasikan dengan:

$$
t=\frac{\hat{\beta}_{j}}{\operatorname{Se}\left(\hat{\beta}_{j}\right)} ; \text { dengan } \operatorname{Se}\left(\hat{\beta}_{j}\right)=\sqrt{\operatorname{var}\left(\hat{\beta}_{j}\right)}
$$

Untuk kriteria penolakannya yaitu $\mathrm{H}_{0}$ ditolak jika $\left|\mathrm{t}_{\text {hitung }}\right|>\mathrm{t}_{(\alpha / 2, n-k-1)}$ atau $p$-value $<\alpha$.

\section{Multikolinieritas}

Multikolinearitas dapat dideteksi dengan menggunakan nilai Variance Inflation Factor (VIF) (Montgomery et al., 1992). VIF didefinisikan melalui rumus sebagai berikut:

$$
\operatorname{VIF}\left(\hat{\beta}_{j}\right)=\frac{1}{\left(1-R_{j}^{2}\right)}, \mathrm{j}=1,2, \ldots, \mathrm{k}
$$

$R_{j}^{2}$ merupakan koefisien determinasi yang didapatkan dengan meregresikan antara suatu variabel bebas dengan variabel bebas lainnya. Menurut menyebutkan bahwa nilai multikolinieritas terjadi apabila VIF $>5$ (Akinwande et al., 2015).

\subsection{Generalized Ridge Regression}

Penaksir pada generalized ridge regression didapatkan dengan melakukan transformasi terlebih dahulu persamaan parameter regresi pada penaksir OLS menjadi bentuk kanonik. Bentuk kanonik yaitu bentuk khusus dari suatu matriks yang dibentuk dengan melakukan diagonalisasi pada matriks asalnya. Devita et al. (2014) mengemukakan apabila dimiliki suatu notasi matriks $\boldsymbol{\Lambda}$ yang merupakan matriks $\mathrm{k}$ x k dengan anggota dari diagonal utamanya adalah eigen value dari matriks $\mathbf{X}^{\mathbf{T}} \mathbf{X}$, kemudian apabila matriks $\mathbf{C}_{\mathbf{k x k}}$ yang merupakan matriks ortogonal dari vektor eigen yang bersesuaian dengan eigen value $\left(\lambda_{j}\right)$ dari $\mathbf{X}^{\mathbf{T}} \mathbf{X}$ maka dapat dituliskan $\boldsymbol{\Lambda}$ kedalam bentuk $\boldsymbol{\Lambda}=\mathbf{C}^{\mathbf{T}} \mathbf{X}^{\mathbf{T}} \mathbf{X C}$. Dimisalkan $\mathbf{X C}=\mathbf{U}$ dan $\mathbf{C}^{\mathbf{T}} \widehat{\boldsymbol{\beta}}=\hat{\boldsymbol{\gamma}}_{\text {OLS }}$, sehingga persamaan regresinya menjadi $\mathbf{Y}=\mathbf{U} \hat{\boldsymbol{\gamma}}_{\text {OLS }}+\boldsymbol{\varepsilon}$. Dengan melakukan transformasi persamaan regresi menjadi bentuk ortogonal persamaan parameternya juga ikut bertransformasi menjadi $\hat{\gamma}_{\text {OLS }}=(\boldsymbol{\Lambda})^{-1} \mathbf{U}^{\mathbf{T}} \mathbf{Y}$.

Menurut Hoerl \& Kennard (1970) parameter regresi ridge diperoleh dengan menambahkan tetapan bias (K) yang bernilai sama untuk setiap variabelnya. Pada generalized ridge regression, tetapan bias yang ditambahkan pada regresi OLS merupakan tetapan bias yang berbeda untuk masing-masing variabel bebasnya pada matriks $\mathbf{X}^{\mathbf{T}} \mathbf{X}$ yang sudah ditransformasi. Sehingga diperoleh parameter gamma generalized yaitu sebagai berikut:

$$
\hat{\boldsymbol{\gamma}}_{\text {Generalizel }}=(\boldsymbol{\Lambda}+\mathbf{K})^{-1} \mathbf{U}^{\mathbf{T}} \mathbf{Y}
$$

Sedangkan $\hat{\boldsymbol{\beta}}$ untuk generalized ridge regression adalah

$$
\hat{\boldsymbol{\beta}}_{\text {Generalized }}=\mathbf{C} \hat{\boldsymbol{\gamma}}_{\text {Generalized }}
$$

$\mathbf{K}$ merupakan matriks bujursangkar yang anggota diagonal utamanya adalah tetapan bias $\left(\mathrm{k}_{1}, \mathrm{k}_{2}, \mathrm{k}_{3}, \ldots, \mathrm{k}_{\mathrm{k}}\right)$. Hoerl \& Kennard (1970) menyebutkan bahwa nilai $\mathrm{k}_{1}, \mathrm{k}_{2}, \mathrm{k}_{3} . ., \mathrm{k}_{\mathrm{k}}$ 
dibangkitkan dengan meminimumkan fungsi MSE dari estimator gamma generalized. Sehingga didapatlah formula untuk menghitung tetapan bias adalah sebagai berikut:

$$
k_{j}=\frac{\sigma^{2}}{\gamma_{j}^{2}}
$$

\subsection{Jackknife Ridge Regression}

Jackknife ridge regression sebagai perkembangan dari metode generalized ridge regression. Parameter jackknife ridge regression didapatkan dengan melakukan resampling jackknife pada parameter generalized ridge regression. Dengan resampling yang dilakukan, akan menyebabkan bias pada metode generalized ridge regression dapat diminimalisir (Singh et al., 1986). Sehingga didapatlah parameter gamma jackknife ridge regression yaitu sebagai berikut:

$$
\hat{\gamma}_{\text {Jacknife }}=\left(\mathbf{I}-\left(\mathbf{A}^{-1} \mathbf{K}\right)^{2}\right) \hat{\gamma}_{\text {oLS }}
$$

Karena $\hat{\boldsymbol{\beta}}=\mathbf{C} \hat{\boldsymbol{\gamma}}$ maka:

$$
\hat{\boldsymbol{\beta}}_{\text {Jackknife }}=\mathbf{C} \hat{\boldsymbol{\gamma}}_{\text {Jackknife }}
$$

\subsection{Modified Jackknife Ridge Regression}

Menurut Batah et al. (2008) penaksir modified jackknife ridge regression menggabungkan ide dari penaksir generalized ridge regression dan jackknife ridge regression, hampir sama dengan penaksir jackknife ridge regression hanya saja pengali parameter OLS pada parameter modified jackknife ridge regression diganti oleh Parameter generalized ridge regression sehingga didapatkanlah penaksir estimasi modified jackknife ridge regression adalah

$$
\begin{aligned}
\hat{\gamma}_{\text {Modified }} & =\left(\mathbf{I}-\left(\mathbf{A}^{-1} \mathbf{K}\right)^{2}\right) \hat{\gamma}_{\text {Generalize d }} \\
& =\left(\mathbf{I}-\left(\mathbf{A}^{-1} \mathbf{K}\right)^{2}\right)\left(\mathbf{I}-\mathbf{A}^{-1} \mathbf{K}\right) \hat{\gamma}_{\text {OLS }} \\
& =\left(\mathbf{I}-\mathbf{A}^{-1} \mathbf{K}-\left(\mathbf{A}^{-1} \mathbf{K}\right)^{2}+\left(\mathbf{A}^{-1} \mathbf{K}\right)^{3}\right) \hat{\gamma}_{\text {OLS }} \\
& =\left(\mathbf{I}-\mathbf{A}^{-1}\left(\mathbf{I}-\mathbf{A}^{-1} \mathbf{K}+\left(\mathbf{A}^{-1} \mathbf{K}\right)^{2}\right) \mathbf{K}\right) \hat{\gamma}_{\text {OLS }}
\end{aligned}
$$

Misalkan $\left(\mathbf{I}-\mathbf{A}^{-1} \mathbf{K}+\left(\mathbf{A}^{-1} \mathbf{K}\right)^{2}\right)=\boldsymbol{\Phi}$ maka

$$
\hat{\gamma}_{\text {Modified }}=\left(\mathbf{I}-\left(\mathbf{A}^{-1} \mathbf{\Phi K}\right)\right) \hat{\gamma}_{\text {oLS }}
$$

Karena $\hat{\boldsymbol{\beta}}=\mathbf{C} \hat{\boldsymbol{\gamma}}$ maka, $\hat{\boldsymbol{\beta}}$ untuk modified jackknife ridge regression dapat dituliskan menjadi

$$
\hat{\boldsymbol{\beta}}_{\text {Modified }}=\mathbf{C} \hat{\boldsymbol{\gamma}}_{\text {Modified }}
$$

\section{METODE PENELITIAN}

\subsection{Sumber Data}

Untuk sumber data sekunder penelitian ini didapatkan pada situs https://ipm.bps.go.id/data/provinsi/metode/baru/3300. Data yang diambil adalah data Indeks Pembangunan Manusia (IPM), Rata-rata Lama Sekolah, dan Harapan Lama Sekolah pada tahun 2018 di Provinsi Jawa Tengah.

\subsection{Variabel Penelitian}

Variabel bebas dan terikat merupakan variabel yang dipergunakan didalam penelitian. Untuk lebih jelasnya mengenai variabel-variabelnya antara lain: 
Y : Indeks Pembangunan Manusia (IPM)

$\mathrm{X}_{1} \quad$ : Rata-rata Lama sekolah

$\mathrm{X}_{2} \quad$ : Harapan Lama sekolah

\subsection{Metode Analisis}

Langkah-langkah analisis yang digunakan untuk mendapatkan model modified jackknife ridge regression:

1) Melakukan input data

2) Melakukan estimasi parameter ordinary least square

3) Pelaksanakan uji F

4) Pelaksanaan uji t

5) Melakukan Uji Asumsi pada regresi ordinary least square (OLS)

6) Melakukan Standarisasi variabel regresi

7) Mencari vektor eigen dan eigen value dari matriks $X^{T} X$

8) Mengalikan parameter OLS dengan konstanta bias sehingga diperoleh nilai $\gamma_{O L S}$

9) Mencari $\operatorname{MSE}\left(\sigma^{2}\right)$ untuk regresi OLS

10) Mencari nilai K(konstanta bias) dengan iterasi HKB. Adapun langkah-langkahnya adalah

a. Mencari nilai K awal dengan cara : $k_{j}^{0}=\frac{\sigma_{o L S}^{2}}{\gamma_{j_{O L S}}^{2}}$

b. Menghitung parameter awal $\hat{\gamma}_{\text {Generalizel }}$ dengan memasukkan nilai k yang udah dicari

c. Menghitung nilai $\hat{\beta}_{\text {Generalized }}$

d. Menghitung $\operatorname{MSE}\left(\sigma^{2}\right)$ baru dengan menggunakan parameter $\hat{\gamma}_{\text {Generalized }}$

e. Menghitung nilai K yang baru dengan cara : $k_{j}^{1}=\frac{\sigma_{\text {Generalized }}^{2}}{\gamma_{j_{\text {Generalized }}}^{2}}$

f. Melakukan cek, iterasi berhenti jika nilai $\left|\left(\hat{\gamma}_{\text {Generalized }}^{\mathrm{T}} \gamma_{\text {Generalized }}\right)^{\mathrm{i}}-\left(\hat{\gamma}_{\text {Generalized }}^{\mathrm{T}} \hat{\gamma}_{\text {Generalized }}\right)^{\mathbf{i}-\mathbf{1}}\right| \leq 0,0001$, jika tidak kembali ke point b, untuk iterasi awal $\left(\hat{\gamma}_{\text {Generalized }}^{\mathbf{T}} \hat{\gamma}_{\text {Generalized }}\right)^{\mathbf{i}-\mathbf{1}}$ merupakan parameter OLS, Sedangkan untuk iterasi seterusnya tetap menggunakan $\hat{\gamma}_{\text {Generalize d }}$ iterasi dengan $\hat{\gamma}_{\text {Generalize d }}$ iterasi sebelumnya

g. Apabila iterasi telah selesai maka akan didapat nilai $\mathrm{K}$ dan parameter generalized ridge regression.

11) Mencari bias $\left(\boldsymbol{\gamma}_{\text {Generalized }}\right)$ dan $\operatorname{bias}\left(\boldsymbol{\beta}_{\text {Generalized }}\right)$

12) Menghitung VIF untuk generalized ridge regression

13) Mencari estimasi parameter jackknife ridge regression

14) Menghitung bias untuk estimasi parameter jackknife ridge regression

15) Mencari VIF untuk jackknife ridge regression

16) Mencari estimasi parameter modified jackknife ridge regression

17) Melakukan uji signifikansi yang berupa uji $\mathrm{F}$ dan uji t pada model modified jackknife ridge regression

18) Menghitung bias untuk estimasi parameter modified jackknife ridge regression 
19) Melakukan uji signifikansi yang berupa uji $\mathrm{F}$ dan uji t untuk generalized ridge regression, jackknife ridge regression, dan modified jackknife ridge regression

\section{HASIL DAN PEMBAHASAN}

\subsection{Analisis Regresi Ordinary Least Square (OLS)}

Model yang diperoleh dengan menggunakan metode OLS adalah sebagai berikut:

$$
\hat{Y}=36,3459+2,7265 \mathrm{X}_{1}+1,1408 \mathrm{X}_{2}
$$

Dilakukan uji $\mathrm{t}$ dan uji $\mathrm{F}$ dengan taraf signifikansi $\alpha=0,05$ dan $\mathrm{n}=35$ dan $\mathrm{k}=2$,

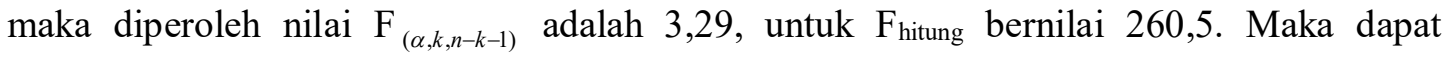
diputuskan bahwa $\mathrm{H}_{0}$ ditolak, sehingga dapat disimpulkan bahwa variabel rata-rata lama sekolah dan harapan lama sekolah secara simultan berpengaruh signifikan terhadap variabel IPM. Selanjutnay dilakukan uji t prosedur pengujian dilakukan dengan membandingkan nilai $\left|t_{\text {hitung }}\right|$ dari masing-masing variabel dengan $\mathrm{t}_{(\alpha / 2, n-k)}$. Dengan taraf signifikansi $\alpha=0,05$ dan $\mathrm{n}=35$ dan $\mathrm{k}=2$, maka diperoleh nilai $\mathrm{t}_{(\alpha / 2, n-k-1)}$ adalah 2,0369. Untuk $\left|t_{\text {hitung }}\right|$ variabel $X_{1}$ bernilai 6,775 dan $\left|t_{\text {hitung }}\right|$ variabel $X_{2}$ adalah 2,102. Maka dapat diputuskan bahwa $\mathrm{H}_{0}$ ditolak, sehingga dapat disimpulkan bahwa masing-masing variabel rata-rata lama sekolah dan harapan lama sekolah secara parsial berpengaruh signifikan terhadap variabel IPM.

\subsection{Pengujian Asumsi Klasik \\ Uji Normalitas}

Untuk menguji normalitas residual, uji yang digunakan adalah uji Kolmogorov Smirnov. Adapun prosedur pengujiannya adalah dengan membandingkan nilai D dengan D $(1-\alpha / 2)$ :

Hipotesis $\quad \mathrm{H}_{0}: \mathrm{F}\left(\varepsilon_{\mathrm{i}}\right)=\mathrm{F}_{\mathrm{H}}\left(\varepsilon_{\mathrm{i}}\right)$, (residual berdistribusi normal)

$$
\mathrm{H}_{1}: \mathrm{F}\left(\varepsilon_{\mathrm{i}}\right) \neq \mathrm{F}_{\mathrm{H}}\left(\varepsilon_{\mathrm{i}}\right) \text {, (residual tidak berdistribusi normal) }
$$

Kriteria penolakannya yaitu $\mathrm{H}_{0}$ ditolak jika $\mathrm{D} \geq \mathrm{d}_{(1-\alpha / 2)}$ atau $p$-value $<\alpha$. Dengan taraf signifikansi $\alpha=0,05$ diperoleh nilai $\mathrm{d}_{(1-\alpha / 2)}$ adalah 0,224 , untuk $\mathrm{D}$ bernilai 0,1389 . Berdasarkan kriteria penolakannya maka dapat diputuskan bahwa $\mathrm{H}_{0}$ ditolak, sehingga dapat disimpulkan bahwa residual berditribusi normal.

\section{Uji Homosgedastisitas}

Untuk menguji homoskedastisitas, uji yang digunakan adalah uji glejser. Adapun prosedur pengujiannya adalah dengan membandingkan nilai $\left|t_{\text {hitung }}\right|$ dengan $\mathrm{t}_{(\alpha / 2, n-k-1)}$.

Hipotesis $\quad \mathrm{H}_{0}$ : terjadi homoskedastisitas

$\mathrm{H}_{1}$ : terjadi heteroskedastisitas

Untuk kriteria penolakannya yaitu $\mathrm{H}_{0}$ ditolak jika $\left|\mathrm{t}_{\text {hitung }}\right|>\mathrm{t}_{(\alpha / 2, n-k-1)}$ atau $p$-value $<\alpha$. Dengan taraf signifikansi $\alpha=0,05$ dan $\mathrm{n}=35$ dan $\mathrm{k}=2$, maka diperoleh nilai $\mathrm{t}_{(\alpha / 2, n-k-1)}$ adalah 2,0369. Untuk $\left|t_{\text {hitung }}\right|$ bernilai 0,079 dan 0,286. Berdasarkan kriteria penolakannya maka dapat diputuskan bahwa $\mathrm{H}_{0}$ diterima, sehingga dapat disimpulkan bahwa residual memiliki variansi yang sama atau terjadi homoskedastisitas.

\section{Multikolinieritas}

Nilai VIF yang diperoleh untuk variabel rata-rata lama sekolah dan Harapan Lama Sekolah adalah 6,8005 lebih besar dari 5, sehingga dapat disimpulkan bahwa terjadi 
masalah multikolinieritas antara variabel bebas. Oleh karena itu diperlukan suatu penanganan untuk mengatasi masalah multikolinieritasnya.

\subsection{Analisis Modified Jackknife Ridge Regression (MJRR)}

Penaksiran parameter regresi dengan metode GRR, JRR, dam MJRR, terlebih dahulu ditaksir nilai $\mathbf{K}$ terbaik dengan menggunakan proses itersi pada metode GRR. Untuk menganalisis dengan metode GRR, JRR, dan MJRR, terlebih dahulu dilakukan standarisasi pada data. Dengan melakukan iterasi pada program RStudio didapatlah nilai konstanta bias terbaik $(\mathbf{K})$ yaitu:

$$
\mathbf{K}=\left[\begin{array}{cc}
0,7328 & 0 \\
0 & 0,1247
\end{array}\right]
$$

Sehingga menghasilkan model regresi untuk GRR, JRR, dan MJRR secara berurutan adalah sebagai berikut:

$$
\begin{aligned}
& \hat{Y}^{*}=0,6937 \mathrm{X}_{1}{ }^{*}+0,2887 \mathrm{X}_{2}{ }^{*} \\
& \hat{Y}^{*}=0,7392 \mathrm{X}_{1}{ }^{*}+0,245 \mathrm{X}_{2}{ }^{*} \\
& \hat{Y}^{*}=0,7036 \mathrm{X}_{1}{ }^{*}+0,2789 \mathrm{X}_{2}{ }^{*}
\end{aligned}
$$

Nilai VIF yang didaptkan dari metode GRR, JRR, dan MJRR secara berturut-turut adalah 1, 1,00008, dan 1,000077. Nilai VIF untuk semua penaksir bernilai kurang dari 5, sehingga dapat disimpulka bahwa metode GRR, JRR, dan MJRR dapat menyelesaikan masalah multikolinieritas dengan baik.

Uji signifikansi koefisien pada GRR, JRR, dan MJRR dapat dilihat pada tabel 1 dan tabel 2 Tabel 1. Tabel ANOVA

\begin{tabular}{ccccccc}
\hline Penaksir & Sumber Variansi & SS & $\begin{array}{c}\text { Derajat } \\
\text { Bebas }\end{array}$ & MSS & F hitung & Kesimpulan \\
\hline \multirow{3}{*}{ GRR } & Regresi & 32,0166 & 1 & 32,0166 & 532,1204 & \\
& Residual & 1,9855 & 33 & 0,064 & & Signifikan \\
& Total & 34,0021 & 34 & & & \\
JRR & Regresi & 32,0328 & 1 & 32,0328 & 536,7846 & \\
& Residual & 1,9693 & 33 & 0,0602 & & Signifikan \\
& Total & 34,0021 & 34 & & & \\
MJRR & Regresi & 32,0219 & 1 & 32,0219 & 533,6391 & \\
& Residual & 1,9802 & 33 & 0,0636 & & Signifikan \\
& Total & 34,0021 & 34 & & & \\
\hline
\end{tabular}

Tabel 2. Tabel uji t

\begin{tabular}{ccccc}
\hline Penaksir & $\hat{\beta}^{*}$ & Standar Error & thitung & Kesimpulan \\
\hline \multirow{2}{*}{ GRR } & 0,6937 & 0,0866 & 8,0088 & Signifikan \\
& 0,2887 & 0,0866 & 3,3326 & Signifikan \\
JRR & 0,7392 & 0,1042 & 7,0947 & Signifikan \\
& 0,245 & 0,1042 & 2,3518 & Signifikan \\
\multirow{2}{*}{ MJRR } & 0,7036 & 0,0904 & 7,7789 & Signifikan \\
& 0,2789 & 0,0904 & 3,0834 & Signifikan \\
\hline
\end{tabular}

Model standarisasi dikembalikan ke model asal, sehingga diperoleh model asal untuk GRR, JRR, dan MJRR secara berurutan adalah sebagai berikut:

$$
\hat{Y}=39,1344+2,5177 X_{1}+1,0476 X_{2}
$$




$$
\begin{aligned}
& \hat{Y}=39,8915+2,6829 X_{1}+0,8893 X_{2} \\
& \hat{Y}=39,3161+2,5533 X_{1}+1,012 X_{2}
\end{aligned}
$$

\section{KESIMPULAN}

Berdasarkan hasil dan pembahasan dapat disimpulkan:

1. Metode GRR, JRR dan MJRR berhasil menyelesaikan masalah multikolinieritas dengan baik, dibuktikan dengan nilai VIF masing-masing penaksirnya lebih kecil dari 5 yaitu VIF untuk GRR, JRR, dan MJRR secara berturut-turut adalah 1, 1,00008, dan 1,000077 .

2. Model regresi untuk hubungan Indeks Pembangunan Manusia (IPM) dengan Rata-rata Lama Sekolah $\left(\mathrm{X}_{1}\right)$ dan Harapan Lama Sekolah $\left(\mathrm{X}_{2}\right)$ menggunakan metode GRR, JRR dan MJRR yaitu:

$$
\begin{aligned}
& \hat{Y}=39,1344+2,5177 X_{1}+1,0476 X_{2} \\
& \hat{Y}=39,8915+2,6829 X_{1}+0,8893 X_{2} \\
& \hat{Y}=39,3161+2,5533 X_{1}+1,012 X_{2}
\end{aligned}
$$

3. MSE yang paling kecil adalah estimasi dengan menggunakan metode JRR yaitu sebesar 0,0602, sehingga dapat disimpulkan bahwa metode JRR adalah metode yang paling baik

\section{DAFTAR PUSTAKA}

Akinwande, M. O., Dikko, H. G., \& Samson, A. 2015. Variance Inflation Factor: As a Condition for the Inclusion of Suppressor Variable(s) in Regression Analysis. Scientific Research Publishing Inc, 754-767.

Batah, F. M., Ramanathan, T. V., \& Gore, S. D. 2008. The Efficiency of Modified Jackknife and Ridge Type Regression Estimators: A Comparison. Surveys in Mathematics and Its Applications, 3(6), 111-122.

Devita, H., Sukarsa, I. G., \& Kencana, I. E. 2014. Kinerja Jackknife Ridge Regression dalam Mengatasi Multikolinieritas. E-Jurnal Matematika, 3(4), 146-153.

Gujarati, D. 1991. Ekonometrika Dasar. Diterjemahkan oleh: Zain S. Jakarta: Erlangga. Terjemahan dari: Basic Econometrics.

Hoerl, A., \& Kennard, R. 1970. Ridge Regression: Biased Estimation for Nonorthogonal Problems. Journal Storage, 12(1), 55-67.

Khurana, M., Chaubey, Y. P., \& Chandra, S. 2014. Jackknifing the Ridge Regression Estimator: A Revisit. Communications in Statistics, 43(24), 5249-5262.

Kim, T. K. 2015. T test as a parametric . Korean Journal of Anesthesiology, 68(6), 540546.

Kurniawan, R., \& Yuniarto, B. 2016. Analisis Regresi Dasar dan Penerapannya dengan R. (E. Wahyudin, Ed.) Depok: Prenadamedia Group.

Manurung, J., Manurung, A., \& Saragih, F. 2005. Ekonometrika Teori dan Aplikasinya. (R. Touran, Ed.) Jakarta: PT Elex Media Komputindo.

Ma'unah, S. 2016. Estimasi Skewness (Kemiringan) dengan Menggunakan Metode Bootstrap dan Metode Jackknife. Universitas Negeri Semarang. Semarang: Library Unnes. 
Montgomery, D., A. Peck, E., \& Vining, G. 1992. Introduction To Linier Regression Analysis. (D. Balding, N. Cressie, G. Fitzmaurice, H. Goldstein, I. Johnstone, G. Molenberghs, et al., Eds.) New York: John Wiley and Sons Inc.

Singh, B., Chaubey, Y., \& Dwivedi, T. 1986. An Almost Unbiased Ridge Estimator. The Indian Journal of Statistics, 48(3), 342-346.

Utami, N. T., Sukarsa, I. G., \& Kencana, I. E. 2013. Penerapan Metode Generalized Ridge Regression dalam Mengatasi Masalah Multikolinieritas. E-Jurnal Matematika, 2(1), 54-59. 